\title{
ON MONOTONE AND POSITIVE SOLUTIONS OF SECOND ORDER NONLINEAR DIFFERENTIAL EQUATIONS
}

\author{
JOHN JONES, JR.
}

1. Introduction. Second order nonlinear differential equations of the type

$$
y^{\prime \prime}+f\left(y, y^{\prime}\right) y^{\prime}+g(y)=0 \quad\left(y^{\prime}=d y / d x\right)
$$

were first investigated by Levinson and Smith [4], and more recently by Utz $[5 ; 6 ; 7 ; 8]$, Antosiewicz [1], G. Brauer [2] and others. For a detailed treatment see Lefschetz [3]. The purpose of this note is to consider the behavior of solutions of (1.1) for large values of the independent variable, assuming the existence of such solutions. A solution is said to be oscillatory if it has positive maxima and negative minima for arbitrarily large values of $x$.

2. Montone solutions. The following result gives sufficient conditions for monotone solutions of (1.1)

THEOREM 1. Let the following conditions be satisfied:

(i) $\phi\left(y, y^{\prime}\right)=f\left(y, y^{\prime}\right) y^{\prime}, f\left(y, y^{\prime}\right) \geqq 0$ for all $y ; y^{\prime}$,

(ii) $y g(y) \geqq 0$ for $y^{\prime} \neq 0$,

(iii) $\int_{0}^{y} g(z) d z \rightarrow \infty$ as $y \rightarrow \infty$,

(iv) $\int_{E}\left\{\left[\phi\left(y, y^{\prime}\right)+g(y)\right] / y^{\prime}\right\} d x \neq \infty$, where $E=\left\{x \mid y(x) \geqq 0, y^{\prime}(x) \geqq 0\right\}$, then a solution $y(x)$, valid for all large $x$, approaches zero monotonically as $x$ tends to infinity.

H. A. Antosiewicz [1] has shown that (i), (ii) and (iii) imply that $|y(x)|$ and $\left|y^{\prime}(x)\right|$ remain bounded as $x \rightarrow \infty$. In [5] W. R. Utz established that (i), (ii), and (iii) also imply that if $y(x)$ is a solution of (1.1) which does not vanish identically, then $y(x)$ is bounded and oscillatory as $x \rightarrow \infty$, or $y(x)$ approaches zero monotonically as $x \rightarrow \infty$. Let us assume that a solution $y(x)$ of (1.1) does not approach zero monotonically as $x \rightarrow \infty$; then $y(x)$ must be oscillatory.

Let $x_{1}$ be a zero of $y(x)$ such that $y$ is negative immediately to the left and positive immediately to the right of $x_{1}$. Then $y^{\prime}\left(x_{1}\right) \geqq 0$. Moreover, if $y^{\prime}\left(x_{1}\right)=0$, then $y^{\prime}(x)>0$ on the immediate right of $x_{1}$ and consequently, $y^{\prime \prime}\left(x_{1}\right)>0$ on the immediate right of $x_{1}$. But this is impossible as (1.1) shows. Hence $y^{\prime}\left(x_{1}\right)>0$. Let $\hat{x}_{1}$ denote the first zero of $y^{\prime}(x)$ to the right of $x_{1}$. By integrating (1.1) over the interval $\left(x_{1}, \hat{x}_{1}\right)$ we have

Received by the editors September 2, 1958 and, in revised form, October 31, 1958. 


$$
y^{\prime}\left(\hat{x}_{1}\right)-y^{\prime}\left(x_{1}\right)+\int_{x_{1}}^{\hat{x}_{1}}\left[\phi\left(y, y^{\prime}\right)+g(y)\right] d x=0 .
$$

Since $y^{\prime}\left(\hat{x}_{1}\right)=0$,

$$
y^{\prime}\left(x_{1}\right)=\int_{x_{1}}^{\hat{x}_{1}}\left[\phi\left(y, y^{\prime}\right)+g(y)\right] d x .
$$

By (ii) $g(y)>0$ for $x_{1}<x<\hat{x}_{1}$. Also $\phi\left(y, y^{\prime}\right) \geqq 0$, and hence $y^{\prime \prime}(x)<0$. Hence $y^{\prime}$ is positive and decreasing on $\left(x_{1}, \hat{x}_{1}\right)$. Thus, by (2.2) we have

$$
\begin{aligned}
1 & =\int_{x_{1}}^{\hat{x}_{1}}\left[\phi\left(y, y^{\prime}\right)+g(y)\right] d x / y^{\prime}\left(x_{1}\right) \\
& \leqq \int_{x_{1}}^{\hat{x}_{1}}\left\{\left[\phi\left(y, y^{\prime}\right)+g(y)\right] / y^{\prime}(x)\right\} d x .
\end{aligned}
$$

It follows from (iv) that the right-hand side of (2.3) tends to zero as $x_{1}$ tends to infinity. Hence, we arrive at a contradiction and $y(x)$ is monotone decreasing to zero as $x \rightarrow \infty$.

3. On positive solutions. The following theorem gives sufficient conditions for the nonexistence of solutions which remain positive for large values of $x$.

Theorem 2. If (i) and (ii) of Theorem 1 hold, and (v) $\left|\phi\left(y, y^{\prime}\right)\right| \leqq g(y)$ for all $y, y^{\prime}$,

(vi) there exist numbers $a$ and $b$ such that $a<b$ and

$$
\int_{b}^{\infty}(x-a)\left[\phi\left(y, y^{\prime}\right)+g(y)\right] d x=\infty,
$$

$$
\left(\phi\left(y, y^{\prime}\right)+g(y)\right)^{1 / 2} \geqq[y(x)]^{2}
$$

then no solution of (1.1) can remain positive for all $x$ greater than $a$.

Suppose that there exists a solution $y(x)$ such that $y(x)>0$ for $x>a$. It follows from (1.1) that $y^{\prime \prime}(x)<0$, so $y^{\prime}(x)$ is decreasing for $x>a$, and $y^{\prime}(x)$ tends either to a finite limit or to $-\infty$. Moreover this limit cannot be negative for then $y(x)$ would become negative. Hence $y(x)$ must be ultimately nondecreasing, and $y^{\prime}(x)$ tends to a finite non-negative limit. If we take $x>a$ and integrate (1.1) over the interval $(x, \infty)$, we obtain:

$$
y^{\prime}(\infty)-y^{\prime}(x)+\int_{x}^{\infty}\left[\phi\left(y, y^{\prime}\right)+g(y)\right] d x=0 .
$$

(The convergence of the integral is guaranteed by the existence of 
$y^{\prime}(\infty)=\lim _{x \rightarrow \infty} y(x)$.) Since $y^{\prime}(\infty) \geqq 0$, we have, by

$$
y^{\prime}(x) \geqq \int_{x}^{\infty}\left[\phi\left(y, y^{\prime}\right)+g(y)\right] d x .
$$

Integrating (3.2) over the interval $(a, x)$ for $x>a$ we have

$$
y(x)-y(a) \geqq \int_{a}^{x} \int_{u}^{\infty}\left[\phi\left(y, y^{\prime}\right)+g(y)\right] d t d u
$$

and thus

$$
y(x) \geqq \int_{a}^{x}(t-a)\left[\phi\left(y, y^{\prime}\right)+g(y)\right] d t .
$$

From (3.4) and by making use of (vii), we have the following inequalities,

$$
\begin{aligned}
& \frac{(x-a)\left[\phi\left(y, y^{\prime}\right)+g(y)\right]^{1 / 2}}{\left\{\int_{a}^{x}(t-a)\left[\phi\left(y, y^{\prime}\right)+g(y)\right] d t\right\}^{2}} \\
& \quad \geqq \frac{[y(x)]^{2}(x-a)}{\left\{\int_{a}^{x}(t-a)\left[\phi\left(y, y^{\prime}\right)+g(y)\right] d t\right\}^{2}} \geqq x-a .
\end{aligned}
$$

If we multiply both sides of $(3.5)$ by $\left[\phi\left(y, y^{\prime}\right)+g(y)\right]^{1 / 2}$, choose $x_{1}$ such that $a<x_{1}$, and integrate (3.5) from $b$ to $x_{1}$ we have

$$
\begin{array}{r}
\int_{b}^{x_{1}}\left\{\int_{a}^{x}(t-a)\left[\phi\left(y, y^{\prime}\right)+g(y)\right] d t\right\}^{-2}\left\{(x-a)\left[\phi\left(y, y^{\prime}\right)+g(y)\right]\right\} d x \\
\geqq \int_{b}^{x_{1}}(t-a)\left[\phi\left(y, y^{\prime}\right)+g(y)\right]^{1 / 2} d t .
\end{array}
$$

As $x_{1} \rightarrow \infty$ the left-hand side of (3.6) remains bounded, hence we reach a contradiction to (vi). Thus $y(x)$ cannot remain positive for all large values of $x$.

REFEREE's REMARK. The author's proof of Theorem 2 also shows that $y(x)$ cannot be negative for all large values of $x$. Thus $y(x)$ changes sign at arbitrarily large $x$-values, that is, $y$ is oscillatory.

\section{REFERENCES}

1. H. A. Antosiewicz, On nonlinear differential equations of the second order with integrable forcing term, J. London Math. Soc. vol. 30 (1955) pp. 64-67. 
2. G. Brauer, Remarks on a paper by Utz, Proc. Amer. Math. Soc. vol. 9 (1958) pp. 34-37.

3. S. Lefschetz, Differential equations: Geometric theory, New York, Interscience Publishers, 1957, Chapter 11.

4. N. Levinson and O. K. Smith, $A$ general equation for relaxation oscillations, Duke Math. J. vol. 9 (1942) pp. 382-403.

5. W. R. Utz, Properties of solutions of certain second order nonlinear differential equations, Proc. Amer. Math. Soc. vol. 8 (1957) pp. 1024-1029.

6. - Boundedness and periodicity of solutions of the generalized Lienard equation, Ann. Mat. Pura Appl. (4) vol. 42 (1956) pp. 313-324.

7. —_ Su una nota di De Castro, Boll. Un. Mat. Ital. (3) vol. 11 (1956) pp. 28-30.

8. - - A note on second order nonlinear differential equations, Proc. Amer. Math. Soc. vol. 7 (1956) pp. 1047-1049.

Air Force Institute of Technology and

University of Tennessee 